\title{
A NOTE ON THE INDUCED POLARIZATION OF THE BUNTER SAND- STONE
}

\author{
R.D. BARKER
}

Instituto de Geociências, Universidade Federal da Bahia, Federação, Salvador (Brazil)

(Received May 2, 1974; accepted December 6, 1974)

\begin{abstract}
Barker, R.D., 1975. A note on the induced polarization of the Bunter Sandstone.

Geoexploration, 13: 227-233.

Laboratory investigations of the induced polarization of the Bunter Sandstone of northwest England have furnished values of frequency effect higher than those normally measured as the background effect in mineral surveys. The variation of measured induced polarization is discussed as a function of the electrolyte salinity, of the applied current frequency, and of the porosity of the sandstone.
\end{abstract}

\section{INTRODUCTION}

To aid the efficient development of ground water resources in Great Britain, the Sub-department of Geophysics, Birmingham University, has been examining the use of geophysical methods in the delineation of high yielding areas of the Bunter Sandstone aquifer of northwest Lancashire. One aspect of the work involved a laboratory study of the induced polarization of the sandstone and its possible relationships with porosity and permeability. Field measurements were also conducted using a McPhar model P650 frequencydomain apparatus. Although the method did not appear to have a useful application to groundwater exploration in this area, considerable information was obtained concerning the induced polarization of the Bunter Sandstone. The laboratory results are presented below and compared with field results.

\section{LABORATORY INVESTIGATIONS}

A total of 121 samples of Bunter Sandstone was selected from borehole cores obtained during the drilling of trial and abstraction wells in northwest Lancashire. From each core was extracted a small cylindrical plug, $4.5 \mathrm{~cm}$ in length and $3.5 \mathrm{~cm}$ in diameter. A standard method of preparation was then followed (Barker and Worthington, 1973a), the samples being saturated with an electrolyte of $300 \mathrm{ppm}$ of $\mathrm{NaCl}$. This concentration was chosen as representative of the groundwater salinity occurring throughout the area from which the samples were collected. 
A simple galvanic resistance-measuring circuit was initially adopted for resistivity measurements. The sample, in series with a standard resistance, was supplied with current from a waveform generator. Measurement of the potential difference across the sample and across the known resistance enabled the resistance of the sample to be calculated. Because the circuit employed a solid state peak detector of comparatively low input impedance $(10 \mathrm{k} \Omega)$, the circuit was modified to the form shown in Fig.1a. A resistance of equal impedance to the peak detector was switched in parallel to either the sample or the known resistance while the peak detector recorded the potential difference across the other. In this way the circuit remained unchanged and the resistance of the sample plus electrolyte, $R_{\mathrm{s}}$, could be computed from:

$R_{\mathrm{S}}=\frac{V_{\mathrm{s}} R_{1} 10^{4}}{V_{1} R_{1}+V_{1} 10^{4}-V_{\mathrm{s}} R_{1}}$

where the variables are defined in Fig.1a.

A normal pre-requisite for obtaining accurate induced-polarization data is the use of correctly prepared, non-polarizing electrodes. Several types of electrode were investigated but all were eventually abandoned in favour of a simple four-electrode system, similar to that described by Sauck and Sumner (1967). Each pair of silver-plated, copper-mesh electrodes was held in a perspex surround which also served as a reservoir for $\mathrm{NaCl}$ electrolyte, through which contact was made with the sample (Fig.1b). When new, the electrodes produced less than $3 \mathrm{mV} \mathrm{DC}$ asymmetry potential which increased after one month's use to around $10 \mathrm{mV}$. The electrodes were not perfectly non-polarizing; however, the electrode polarization correction for a certain sample was easily determined by measurements across containers of pure electrolyte having the same resistance as the sample.

To measure the resistance of a sandstone core, four voltage readings were made: two (one reversed) across $R_{1}$ and two (one reversed) across the sample. An average for each two readings was computed and substituted in eq.1 to calculate the resistance of the sandstone plus electrolyte. A correction for the resistance of the electrolyte occurring between each potential electrode and the sample was then made.

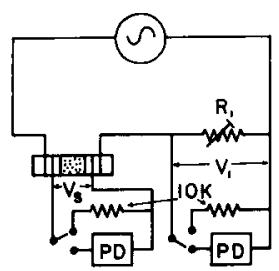

(a)

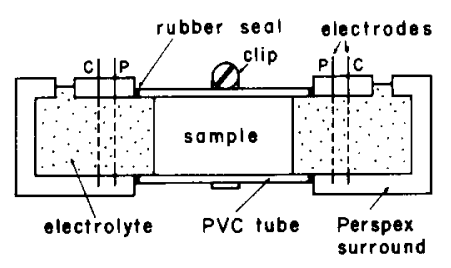

(b)

Fig.1. (a) Circuit for measurement of frequency effect, $V_{\mathrm{S}}$ and $V_{1}$ are the differences in potential measured across the sample and the standard resistance, $R_{1}$, respectively. (b) Four-electrode resistivity cell. 
The resistivity of each sandstone core was determined at frequencies of 5.0 and $0.5 \mathrm{~Hz}$ and the percent frequency effect, PFE, calculated from:

$\mathrm{PFE}=\left[\frac{\rho(0.5)-\rho(5.0)}{\rho(5.0)}\right] 100$

All frequency-effect measurements were conducted at a current density of approximately $40 \mu \mathrm{A} \mathrm{cm}^{-2}$ which, because of practical limitations, is higher than current densities normally encountered in field surveys. Laboratory studies made by Scott and West (1969) suggest that measurements of induced polarization conducted at $40 \mu \mathrm{A} \mathrm{cm}^{-2}$ should differ by less than $10 \%$ from field observations.

Repeatability tests showed that induced polarization could be measured with an accuracy of $\pm 0.5 \%$ frequency effect.

\section{RESULTS}

The variation of sandstone conductivity with frequency of the applied current was determined for selected sandstone cores. The results, presented in the form of conductivity spectra normalized to a frequency of $5,000 \mathrm{~Hz}$ (Fig.2), give curves with a slight upward convexity. These agree with the results of Fraser et al. (1964) who reach the general conclusion that conductivity spectra of sedimentary rocks are characterized by an upward convexity.

For a group of ten samples, induced-polarization measurements were made at four electrolyte concentrations. In all cases the percent frequency effect fell with decrease in electrolyte activity. Fig. 3 shows the average variation of frequency effect with electrolyte resistivity. Although this agrees with Collett (1959), who shows the same general relationship for samples exhibiting membrane polarization, other workers have observed contrary results. Vacquier

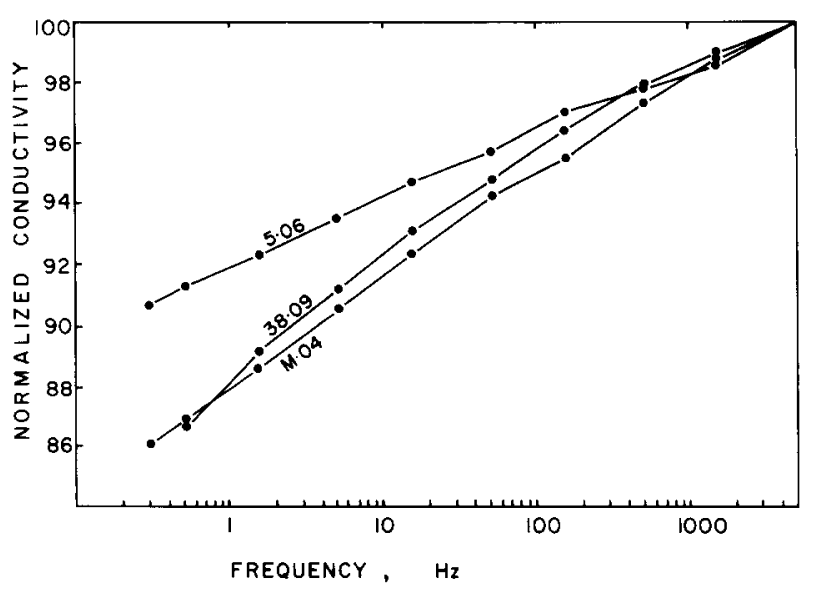

Fig. 2. Conductivity spectra of 3 specimens (5.06, 38.09 and M.04) of Bunter Sandstone. 


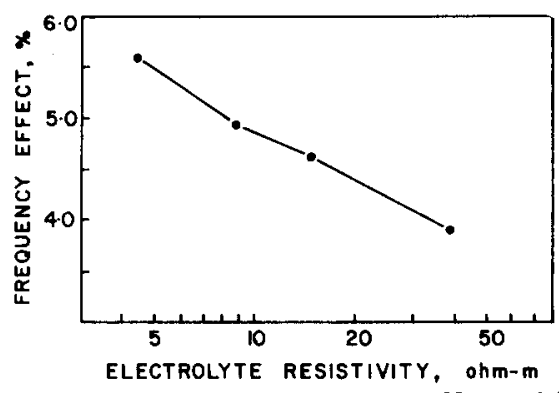

Fig. 3. Variation of frequency effect with electrolyte resistivity. Each point is the mean of observations on 12 samples.

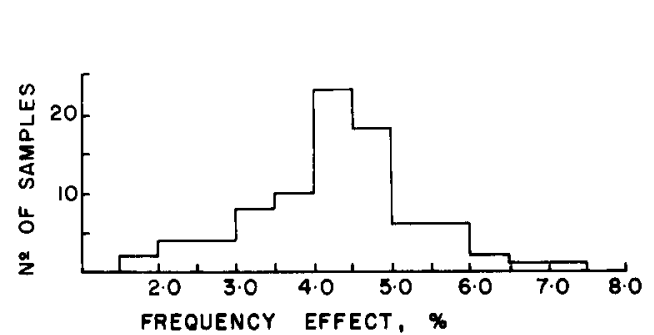

(a)

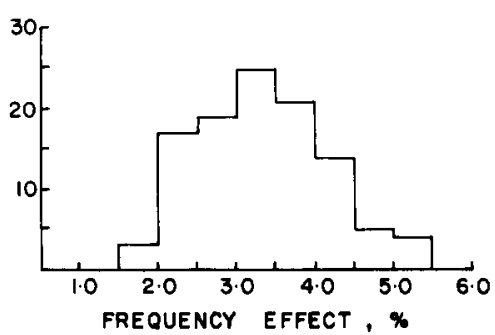

(b)

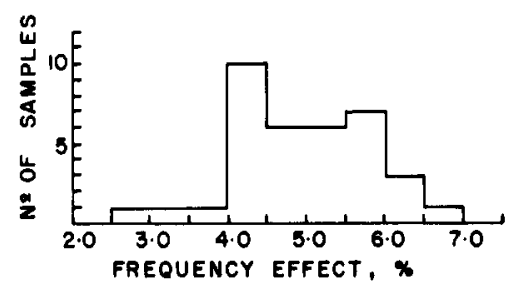

(c)

Fig.4. Frequency distributions of percent frequency effect. (a) laboratory measurements on horizontally oriented samples; (b) field measurements; and (c), laboratory measurements on vertically oriented samples.

et al. (1957), for example, found that polarizability increases with decreasing electrolyte activity. He suggests that the magnitude of the induced polarization depends in a complex way on the resistivity of the solution, on the amount of the clay, and on the particular cation saturating the clay.

The results of frequency-effect measurements on 85 samples, oriented parallel to the observed stratification are presented in Fig.4a in the form of a frequency distribution. Also shown (Fig.4b) are values of frequency effect obtained by the interpretation of 108 induced-polarization soundings conducted in the same area. Although the frequencies used in the field were $0.3125 \mathrm{~Hz}$ and $5.0 \mathrm{~Hz}$, the results have been normalized to a common decade base. The field measured values are, in general, fractionally lower than laboratory measurements. Average values are summarized in Table I. 


\section{TABLE I}

Mean values and associated standard deviations of laboratory and field measured frequency effect

\begin{tabular}{llll}
\hline & mean PFE & $\begin{array}{l}\text { Standard } \\
\text { deviation }\end{array}$ & $\begin{array}{l}\text { No. of samples } \\
\text { measured }\end{array}$ \\
\hline $\begin{array}{l}\text { laboratory measurements } \\
\quad \text { horizontal samples }\end{array}$ & 4.3 & 1.1 & 85 \\
$\quad$ vertical samples & 4.9 & 0.9 & 36 \\
field measurements & 3.2 & 0.8 & 108 \\
\hline
\end{tabular}

The results of measurements on 36 samples oriented perpendicular to the bedding are shown in Fig.4c. Comparison with Fig.4a suggests that induced polarization in the Bunter Sandstone varies with direction of measurement. Anisotropy was further examined by measurements on pairs of samples, each pair comprising one horizontally oriented sample and one taken immediately adjacent to the first in a vertical direction. Of 24 pairs measured, 18 showed an increase in frequency effect in a vertical direction (Fig.5). In general, vertical frequency effect is $12 \%$ greater than that measured horizontally.

Barker and Worthington (1973b) also recorded a significant anisotropy in measurements of permeability and apparent formation factor. They suggest that this is caused by the preferred orientation of tabular minerals. The principal constituents of the Bunter Sandstone are quartz, clay minerals, and haematite. Of these, the clays and haematite have a complex chemistry and minor variations in their composition and distribution within the sandstone could greatly affect the measured induced polarization.

Because of the complex mineralogy of the sandstone, it was not surprising when an experimental study of possible relationships between frequency ef-

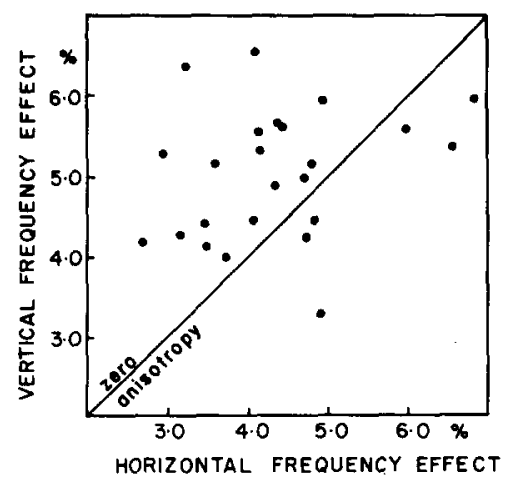

Fig. 5. Comparison of percent frequency effect of 24 vertical and horizontal Bunter Sandstone samples. 


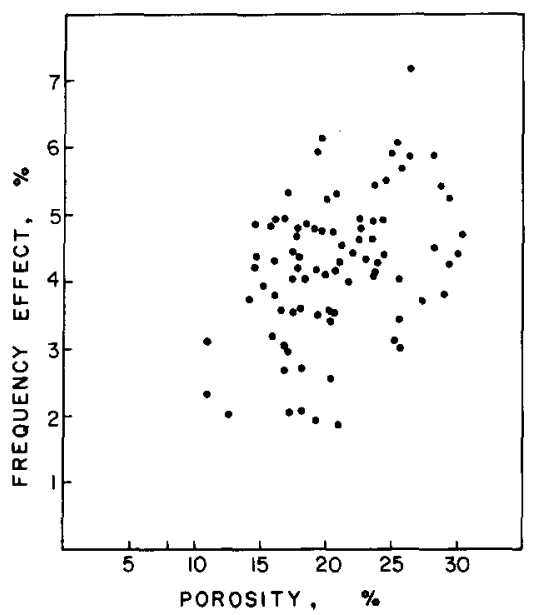

Fig.6. Variation of percent frequency effect with porosity.

fect and other physical properties yielded few positive results. The most significant relationship was observed not between PFE and permeability or clay content of the sandstone as might have been expected (Dakhnov, 1962), but between PFE and porosity (Fig.6). However, even here the distribution of points is too random to predict confidently a relationship between these two parameters.

\section{CONCLUSIONS}

It is interesting to note that the induced polarization of the Bunter Sandstone is generally higher than that measured as the background effect in mineral surveys and sometimes higher than measurements over disseminated ore bodies (Hallof and Winniski, 1971). It is probable that the observed values include contributions from the clay minerals (membrane polarization) and from the haematite and other impurities (electrode polarization).

The Bunter Sandstone provides one example of a common Tertiary rock which is characterized by a comparatively high percent frequency effect. However, further studies of other sedimentary formations will be necessary before the induced-polarization method can be used as an important complement to other geophysical techniques in non-mineralized terrains.

\section{REFERENCES}

Barker, R.D. and Worthington, P.F., 1973a. Some hydrogeophysical properties of the Bunter Sandstone of northwest England. Geoexploration, 11:151-170

Barker, R.D. and Worthington, P.F., 1973b. The hydrological and electrical anisotropy of the Bunter Sandstone of Northwest Lancashire. Q.J. Eng. Geol., 6: 169-175

Collett, L.S., 1959. Laboratory investigations of overvoltage. In: J.R. Wait (Editor), Overvoltage Research and Geophysical Applications. Pergamon Press, London, 158 pp. 
Dakhñov, V.N., 1962. Geophysical well logging. Q. Colo. Sch. Mines, 57: 374-818

Fraser, D.C., Keevil, N.B., Jr. and Ward, S.H., 1964. Conductivity spectra of rocks from the Craigmont ore environment. Geophysics, 29: 832-847

Hallof, P.G. and Winniski, E., 1971. A geophysical case history of the Lakeshore ore body. Geophysics, 36: 1232-1249

Sauck, W.A. and Sumner, J.S., 1967. Laboratory experiments in induced polarization. Annu. Int. Meet., Soc. Explor. Geophysicists, 37 th, Oklahoma City, Okla. (pre-print)

Scott, W.J. and West, G.F., 1969. Induced polarization of synthetic, high resistivity rocks containing disseminated sulphides. Geophysics, 34: 87-100

Vacquier, V., Holmes, C.R., Kintzinger, P.R. and Lavergne, M., 1957. Prospecting for ground water by induced electrical polarization. Geophysics, $22: 660-687$ 